\title{
Which Complexity Characteristics Do Economical Industries Present?
}

\author{
Rafael Aita
}

Industrial Engineering Department, University of Lima, Lima 15023, Peru

Corresponding Author Email: raita@ulima.edu.pe

https://doi.org/10.18280/ijdne.150206

Received: 15 December 2019

Accepted: 26 February 2020

\section{Keywords:}

complexity, economic industry, chaos

\begin{abstract}
The past decade has seen a development of complex theories in different fields, raising the question: should managers use complex principles in their strategy? The answer implies to analyze companies and economical industries where they develop as a complex system. This paper study seven characteristics that define complex systems and analyzes if they can be observed in economical industries.
\end{abstract}

\section{INTRODUCTION}

In everyday speech, the word complexity is often used as a synonym for complicated, confusing or difficult to understand. However, science gives a specific meaning to this term. According to Rzevski [1], complex systems are open systems composed of a large number of diverse, partially autonomous and that they interact among each other. These elements are known as agents and are not centrally controlled. The overall behavior of complex systems emerges from the interaction between agents, which is unpredictable, but not random. According to Stephen Wolfram [2], complex behavior is at the last step in the classification of behaviors for a dynamic system, which are classified as:

- Class I: Stable and homogeneous behavior

A very simple behavior, regardless of the variations in the initial conditions, it will be reached almost to the same final state.

- Class II: Stable and periodic behavior

This behavior can derive in several different final states, but they all consist of simple structures that remain constant or are repeated every certain time interval.

- Class III: Chaotic behavior

A more complicated type of behavior, at first glance seems totally random, however it shows a repetitive order between the different levels in the structures of the system.

- Class IV: Complex behavior

It shows a mix of order and randomness. The local structures of the system are simple, but they move and interact with each other in a complicated way.

\section{COMPLEXITY IN MANAGEMENT}

Complexity research became prominent in management in the 1990s. Relationship between complexity and uncertainty has been studied by Merry [3], Lane and Maxfield [4], Black and Farias [5], Conner [6] and Mason [7]. They all agree that any system has the property to increase its complexity on time and therefore, its unpredictability. More complexity means a greater change rate so change adaptability turns more difficult and forecast is lees accurate.

Farjoun and Levin [8] agree that long term unpredictability is a great challenge for management by introducing uncertainty and restricting their capability to control, coordinate and allocate resources effectively.

Management theory still maintain classic strategic planning structures developed during the 20th century, in some cases, sticking to the taylorian principles of the industrial revolution [9], considering the following assumptions that are not true in chaotic environments:

- Obsolete information at the end of the process $[10,11]$ cited in the work [12].

- Assuming that the organization is in a stable environment $[13,14]$.

- Assume, therefore, that the organization can control its environment $[12,15,16]$.

Current management models are designed for stable environments and doesn't show how to adapt to change in chaotic environments. This problem is relevant since most authors in chaos and complexity agree that traditional strategic design is not effective in this type of environment [10, 17-19], cited in the work [7].

To understand the concepts of chaos and complexity is necessary study the origin of complex theories and review their historical evolution. The science of chaos was born with mathematician and meteorologist Edward Lorenz [20], followed by Mandelbrot [21], Prigogine [22], Morín [23] among the most outstanding theorists. Chaos theory has also been applied to explain complexity in business management, like supply chain dynamics [24-26] and Tsoukas [27] used it as a framework for organizational theory, Gabriel [28] challenged the myth of managerial control, Anderson [29], Boisot and Child [30] and Frank and Fahrbach [31] used chaos theory to provide models that describes organizations as adaptive systems. Stacey [32, 33] and Lissack [34] applied chaos theory to explain strategies and the generation of business strategies. Beeson and Davies [35] identified complexity concepts in the study of organizational change and information systems. Dhillon and Ward [36] applied chaos theory to analyze quantitative data from information strategy 
studies. Merali [37] explored concepts of complexity theory in describing the network phenomenology of information systems [38]. More recently, Velásquez and Restrepo [39] demonstrated the chaotic behavior of the stock exchanges in Colombia, Chile and Peru, while Ndofor et al. [40] did the same with the behavior of 19 industries in the United States.

Chaos theory was originally developed in the context of the exact sciences but found fertile ground in other fields. Radzicki [41] and Butler [42] pointed out that social, ecological and economic systems also have non-linear characteristics and complex evolving interactions over time.

Theory of catastrophes is another effort to model the abrupt change effects on a system. Proposed by Thom [43], theory of catastrophes is a mathematical theory to model the structural stability of practical systems. It was applied to business by Graham \& Seltzer [44] and Wright [45] used it to study the decision making and business processes. Catastrophe theory seeks to represent the topological structure of a system to identify the equilibrium breakpoints called catastrophes. This theory distinguishes between different types of topologies in catastrophes, such as the fold or the cusp. However, it didn't make an impact on the administration literature since these proposals.

Most authors on chaos and complexity agree that traditional strategic design is ineffective in a chaotic environment $[10,17-$ 19], cited in the work [7]. Some of these studies focus on the structure of the SWOT analysis, such as the one carried out by Hill and Westbrook [46]. They conclude that the SWOT analysis was inefficient in the companies they studied, both as an analysis tool and as part of the strategic review. According to the authors, SWOT analysis survives because of its direct methodology, requiring little preparation to perform. Likewise, Panagiotou [47] describes SWOT methodology as vague, very simplified and with many limitations.

If we analyze traditional strategic planning structure, we will find that it is based on the following process division: formulation, implementation and evaluation. This model follows the classic principle of system analysis which divides the system in elements in order to study the nature of each element separately. This analytic method ignores the emergent properties raised from the interactions of the elements according to the definition of complexity of Rzevski [48], as well as the degrees of uncertainty in each element.

SWOT Matrix is the heart of the strategic formulation and is structurally based on the principles of classical logic. It assumes that if two propositions, $\mathrm{p}$ and $\mathrm{q}$ are true, then the result will also be true. This principle of classical logic is reflected in strategy design in SWOT Matrix as follows:

If STRENGTH and OPPORTUNITY happens, then STRATEGY 1.

If STRENGTH and THREAT happens, then STRATEGY 2 .

If WEAKNESS and OPPORTUNITY happens, then STRATEGY 3.

If WEAKNESS and THREAT happens, then STRATEGY 4.

Pérez and Massoni [49] affirm that the classic paradigm is based on several assumptions that, although they have evolved over time, maintain their overall settings designed for more stable environments:

- Assumption of economic rationality: Calculations can be known as rational by an observer.

- Assumption of managerial and organizational unity: organization acts hierarchically

- Functionalist teleological pragmatism: coupled with an approach based on linearity and balance.

- Assumption that environment is fixed.

This planning problem in chaotic environments lies not only in the traditional structure of the model, but also in mental models that senior managers generate by using the classic strategic planning and prevents them from responding to environmental changing conditions. For example, Henderson, Miller and Hambrick [50] claim that the mismatch between CEOs' mental paradigms and change in dynamic external conditions is the cause of the lack of adaptation. Smallman [51] says that managers need to move from the current reactive paradigm to a proactive and holistic paradigm according to the changing environment. Meyer et al. [52] affirm that from time to time, organizational environments go through cataclysmic changes so sudden and extensive that they alter the trajectory of entire industries, overwhelming their adaptive capacity and exceeding the managers understanding. He adds that administration theory offers little help in dealing with these situations. Prahalad and Hamel [53] confirm that many assumptions rooted in traditional strategic models may be incomplete or outdated. This reality forces us to reexamine the paradigms of traditional strategic planning

Nonlinear methods have been used to demonstrate complex behavior on economical industries, most of them proven their hypothesis successfully [40] arising the question: which complex characteristics does economic industries present? Rzevski [1] grants seven specific characteristics to complex systems:

1. Self-organization: Complex systems have a tendency to react to disruptive events by recomposing themselves autonomously in order to eliminate, or at least reduce, the effects of disruption.

2. Autonomy: Agents have freedom of action, with a limit of restrictions given by the rules, rules and regulations of the system.

3. No balance: Complex systems are subject to change. This change is not linear, but a succession of discrete and disruptive events as well as small imperceptible changes.

4. Emergency: The behaviour of a complex system emerges from agent interactions, being totally unpredictable, but not random.

5. Co-evolution: Complex systems change adapting to the environment while changing their environment at the same time.

6. Connectivity: Agents, or system elements, are interconnected. The complexity of the system increases with the number of connections.

7. Nonlinearity: The relationships between agents are nonlinear, which means that a small cause can be amplified to generate a consequence of large magnitudes.

These characteristics are presented in different levels in industry. That is why an analysis of each one will be done.

\section{SELF-ORGANIZATION, AUTONOMY, NON- EQUILIBRIUM AND DISSIPATIVE STRUCTURES}

We will begin by studying these characteristics by comparing the company with a dissipative structure and 
analyzing how they are presented within this type of structures. Ilya Prigogine [22] defined dissipative structures as systems that subsist thanks to the exchange of energy they make with the environment, also explaining that a functional structure, the more complex it is, the more energy it will require to maintain all its connections. In that case, the system is more unstable and is said to be "further from equilibrium". Therefore, the increase in order and complexity brings a price which is a greater dependence on energy and a greater vulnerability of the system. To counteract this vulnerability, these systems carry out a process of spontaneous "selforganization" through which the system recovers its balance; it is modified and coupled with its immediate surroundings. At the center of this self-organization, we can find the spontaneous structuring in a hierarchy of levels (which we can see in cells, organs, systems, bodies). According to Resnick: "The interrelations between the elements of one level originate new types of elements in another level, which behave in a very different way" [54]. This allows the systems to reduce vulnerability from the increased complexity of the system, therefore, to be more resistant to environmental disturbances, changing, adapting to them and at the same time increasing their level of internal complexity gradually and dangerously moving away from its balance. At this stage, the systems are stable despite being far from equilibrium, as a kind of dynamic equilibrium. This state is called non-equilibrium. The system can move away from equilibrium to a certain extent, since there comes a time when the system is so complex that in the event of a small disturbance, it collapses, unleashing a period of turbulence, a phase of readjustment of its parts in which the system is rearranged to reach a new balance. This last state of equilibrium will be just a transition, a period of "entropic rest" in Prigogine's words; until the new period of turbulence and non-equilibrium arrives. These intervals of successive periods of entropic rest and turbulence are characteristic in complex systems and can also be observed in the evolution of industrial sectors.

The first step in determining if an industrial sector shows the characteristics of a complex system will be to analyze whether the industrial sectors present the characteristics mentioned here. In the first place, can we compare a business organization (either company or industrial sector) with a dissipative structure? An organization can be defined as a dissipative structure if the following characteristics are accepted; open, non-linear, dynamic and at the same time stable (non-equilibrium) and it exchanges energy and matter with its environment. Along these lines, Prigogine [22] has applied the dynamics of dissipative structures to the organizational change. Organizations move within the spectrum between seasonality and complex adaptability [55]. Under this perspective of dissipative structure, the authors detect that the organization goes through cycles of evolution and revolution similar to the phases that Niell identifies that pass through dissipative structures. Niell [56] detects two key moments in the evolution of a dissipative structure: the moments of transition between phases and the moments of development (also called "periods of entropic rest" by Prigogine) that coincide with energy dissipation and flow minimization of energy. The succession of these cycles puts the company in a permanent state of "dynamic equilibrium" called a state of non-equilibrium. The differential of continuous inputs and outputs generates a non-equilibrium state in organizations that will allow it to grow and adapt to changes in its environment with greater flexibility than a static equilibrium, which is much more rigid in the face of external influences. The first conclusion we can find is that the periods of crisis are not negative, but that they are part of a natural process that allows the system to adapt to the new rules of the environment and be reborn stronger, so this dynamism provides greater stability, adaptability and flexibility to companies in the sector. Even so, this dynamic equilibrium has its disadvantages, since the dissipative structure, the more intricately connected it is, the more energy it will need to maintain these connections, in turn becoming more vulnerable to external forces. Therefore, both the organization and the sector where it is located, as they grow, they will need new forms of organization that allow them to recover the simplicity of a basic structure. It is at that moment that a hierarchy of levels emerges that show self-similarity, transitivity, with each other. This hierarchy of levels can be observed in the functional organization of the Company. As a company grows in complexity, it is necessary to divide it into departments and areas that show a characteristic of self-similarity with the higher level so typical of complex systems, exactly the same as the hierarchy in which systems, organs and human body cells are divided. This hierarchy does not end in the company, but continues towards the sectors and macro industrial sectors. Here we will stop to make a new difference. Companies are organized under the direction of a head that designs the structure of the organization, this cancels the characteristic of self-organization, typical of complex systems. Indeed, the functional division within the company, although effective and necessary, is not spontaneous, but has been implemented vertically throughout the organization. However, from there, the new structures (sectors and macro sectors) only show regulatory bodies, but not a head that designs and directs the form of organization of the sector or macro sector. It can be stated then that the industrial sectors are fulfilling the characteristics of a complex system, but not the companies. The characteristic of self-organization in the industrial sectors may not be seen very clearly since they do not become consolidated in an organization itself. That is why at this point it is necessary to make a difference and say that an industrial sector does not necessarily form a complex system as it is not an autonomous and spontaneous organization itself, but these properties can be found in Michael Porter's industrial clusters [57].

\section{EMERGENCE, CO-EVOLUTION AND CLUSTERS}

If companies do not comply with the self-organization characteristic, the industrial sectors do not necessarily comply with the emergency characteristic. It is not usual to see global properties that arise (emerge) spontaneously from the interaction of agents or elements in an industrial sector, and that are not found in the agents themselves. However, these properties can be found in the industrial clusters of Michael Porter. Porter [57] defines clusters as geographical concentrations of interconnected companies and institutions, which operate in a specific field. They group together a wide range of industries and other related entities that are important to compete. They include, for example, suppliers of critical inputs - such as components, machinery and services - and providers of specialized infrastructure. Porter [58] adds that in many cases the cluster is also extended to channels, customers and manufacturers of complementary products. One of the requirements of the cluster is that it is concentrated in a limited 
geographical region, which leads Porter to wonder what force leads a group of companies to join without prior coordination in a given geographical area. The answer to that question is found in the self-organization characteristic, explained in the previous section, which describes how a complex system can organize itself spontaneously without a clearly attributable cause. But in addition to self-organization, Porter's clusters show emerging properties of their own interaction. According to Porter in the same article, the interaction of companies within the cluster increases the productivity of companies based in the area, imposes the pace of innovation and encourages the formation of new companies that strengthens the cluster. These three are emergent properties that are not found in any of the isolated elements, but arise spontaneously from the interaction of the agents. These same emergent properties lead to the co-evolution of the system. According to Porter [58], the clusters encourage competition and cooperation. The competition is clear between rival companies in a cluster, but what is often overlooked is cooperation between agents, especially vertical cooperation of companies that participate in related industries and local institutions. This combination of competence and cooperation leads to a coevolution of the agents in the cluster. That is why Porter states: "peer pressure and a desire to enjoy a good reputation in the local community encourage executives to better themselves" [57].

\section{CONECTIVITY, NON-LINEARITY AND SUPPLY CHAINS}

Finally, the last properties can be detected in the structure of a supply chain. The connectivity is given through the exchange of goods and services that occurs through a supply chain. This exchange moves away more and more from a chain approaching a network thanks to the intervention of other agents such as lenders, exchange platforms, logistics operators, etc.; which increases the complexity of the system. The greater the degree of connectivity of the system, the more robust it is, but at the same time it also increases its complexity, making characteristic of self-organization more necessary. The connectivity of a supply chain is maximized in an industrial cluster, so that non-linearity across the chain, which is also present, even in the supply chains of industrial sectors that do not form a cluster. Prigogine [22] had already noted that after the transition periods between phases of the dissipative structures previously described, bifurcation points are presented where the system can be inclined, randomly or induced, by one or more paths. These bifurcation points are also sensitive to the initial conditions so that the smallest fluctuation can induce the system to lean towards one or the other path. According to the initial definition, we are precisely facing the property of non-linearity, which consists in the fact that a small cause can generate consequences of great magnitudes. In addition to the periods of phase transition (which can be clearly identified with periods of economic crisis or restructuring of a sector), non-linearity is also observable in the so-called whip effect within supply chains.

The whip effect was first identified by $P \& G$ by noting the different ranges of variability of its product, Pampers throughout the entire distribution chain. According to the article published by Lee et al. [59], the variability in the demand for diapers in the retailer was small (babies consume diapers at a constant rate), however the variability of demand at different points in the chain of distribution was growing inexplicably. When looking at the back of the chain and comparing the variability in demand with the variability in orders from its suppliers, such as $3 \mathrm{M}$, the latter was even greater, as if the variability grew as you move further away from the market regardless of the fluctuations in customer orders. Hewlett-Packard found the same phenomenon as Bristol-Myers Squibb, McKesson or Longs Drug Stores, so the effect is presented regardless of the industry or sector where the company is located.

The increase in variability shows that these systems are nonlinear, since a small variation in the level of inventories generates large fluctuations in demand.

\section{CONCLUSIONS}

- We cannot say that the company, or even the industrial sectors, show all the characteristics of a complex system. In the case of business organizations it is not possible to see the property of self-organization since all of them are structured from a head that dictates their design and order. Industrial sectors, on the other hand, do not necessarily show the characteristic of emergency, where new properties arise that are not found in any of the elements, but as a result of the interactions of the elements. These characteristics of complex systems are seen mainly in the clusters described by Michael Porter, so we can say that a cluster meets all the characteristics of a complex system.

- Focusing on the cluster as a complex system represents a profound modification in its analysis and study. The characteristics of a complex system cannot be deduced from the properties of its parts, but are the result of a "supramolecular organization" that emerges spontaneously from the system. This implies that the question posed by Porter to solve in a cluster: What force leads a group of companies to join without prior coordination in a given geographical area? loses meaning, since this phenomenon occurs as a result of the selforganization, emergency and non-linear properties of a complex system.

- The classic strategic tools that seek to analyze the system by disaggregating it into its components leave out important emerging properties of the system when it is a cluster and are not even fully applicable to the analysis of the environment and internal of a company. To study these properties, a holistic approach must be taken that prioritizes the exchange of energy of the system with its environment according to the behavior of dissipative structures. This energy exchange is made up of different flows in and out of the system. The main inflow and outflow are the flow of money, which is quantified by Business Accounting. A second flow consists of the flow of materials, which is quantified and controlled by Logistics and business production plans. There is also a third flow that has gained special importance in recent years, becoming one of the main sources of value generation in the Information and Knowledge Age: the flow of information. The system is immersed in a continuous updating and outdating of information, the cluster itself generates information towards the environment as well as receives information from it.

- The evolution of the clusters shows the dynamic behavior of a dissipative structure, the succession of periods of 
crisis and stability are a reflection of the succession of periods of phase transitions and entropic rest of dissipative structures. The property of nonlinearity, where a small cause can generate a great effect causes the level of uncertainty to grow in this evolutionary process. The property of self-organization, however, means that the system can be rearranged after the period of crisis and adjust to the new environmental conditions.

\section{REFERENCES}

[1] Rzevski, G. (2015). Complexity as the defining feature of the 21st century. International Journal of Design \& Nature and Ecodynamics, 10(3): 191-198. https://doi.org/10.2495/DNE-V10-N3-191-198

[2] Wolfram, S. (2002). A New Kind of Science. Champaign, IL: Wolfram media.

[3] Merry, U. (1995). Coping with Uncertainty: Insights from the New Sciences of Chaos, Self-Organization, and Complexity. Praeger, Westport, CT.

[4] Lane, D., Maxfield, R. (1996). Strategy under complexity: fostering generative relationships. Long Range Planning, 29(2): 215-31. https://doi.org/10.1016/0024-6301(96)00011-8

[5] Black, J., Farias, G. (1997). Genesis of complexity cycles. 8th Annual International Conference of The Society for Chaos Theory in Psychology and Life Sciences, Boston University, Boston, MA.

[6] Conner, D.R. (1998). Leading at the Edge of Chaos: How to Create the Nimble Organization. John Wiley, New York, NY.

[7] Mason, R.B. (2007). The external environment's effect on management and strategy: A complexity theory approach. Management Decision, 45(1): 10-28.

[8] Farjoun, M., Levin, M. (2011). A fractal approach to industry dynamism. Organization Studies, 32(6): 825851. https://doi.org/10.1177\%2F0170840611410817

[9] Hamel, G., Prahalad, C.K. (1994). Competing for the Future. Harvard Business School Press, Boston, MA.

[10] Nilson, T.H. (1995). Chaos Marketing: How to Win in a Turbulent World. McGraw-Hill, London.

[11] Loewen, J. (1997). The Power of Strategy: A Practical Guide for South African Managers. Zebra, Sandton.

[12] White, D.W. (1998). The impact of environmental uncertainty on strategy creation style in a franchise channel setting. Journal of Strategic Marketing, 6: 273304. https://doi.org/10.1080/096525498346568

[13] Volberda, H.W. (1997). Building flexible organizations for fast-moving markets. Long Range Planning, 30(2): 169-83. https://doi.org/10.1016/S0024-6301(96)00110-0

[14] Chakravarthy, B. (1997). A new strategy framework for coping with turbulence. Sloan Management Review, Winter, pp. 69-82.

[15] Goold, M., Quinn, J.J. (1990). The paradox of strategic controls. Strategic Management Journal, 11(1): 43-57. https://doi.org/10.1002/smj.4250110104

[16] Cravens, D.W. (1991). Strategic Marketing. 3rd ed., Irwin, Homewood, IL.

[17] Edgar, D.A., Nisbet, L. (1995). Strategy in a small business - a case of sheer chaos. Internet ConferenceHospitality Industries: Strategies for the future, International Journal of Contemporary Hospitality Management.
[18] Brown, S.L., Eisenhardt, K.M. (1998). Competing on the Edge: Strategy as Structured Chaos. Harvard Business School Press, Boston, MA.

[19] Roos, J. (1999). Strategy making. Managing the Complex, Proceedings of Conference at New England Complex Systems Institute, Boston, MA.

[20] Lorenz, E.N. (1963). Deterministic nonperiodic flow. Journal of the Atmospheric Sciences, 20(2): 130-141.

[21] Mandelbrot, B. (1967). How long is the coast of Britain? Statistical self-similarity and fractional dimension. Science, $\quad$ 156(3775): 636-638. https://doi.org/10.1126/science.156.3775.636

[22] Prigogine, I. (1993). Las leyes del caos. Traducido por Juan Vivanco. Editorial Crítica S.L., España.

[23] Morín, É. (2007). Introducción al conocimiento complejo. Editorial Gedisa, S.A. España.

[24] Levy, D. (1994). Chaos theory and strategy: Theory, application, and managerial implications. Strategic Management Journal, 15(S2): 167-178. https://doi.org/10.1002/smj.4250151011

[25] Griffin, D., Shaw, P., Stacey, R. (1998). Speaking of complexity in management theory and practice. Organisation, 5: 315-339. https://doi.org/10.1177\%2F135050849853002

[26] Chia, R. (1998). From complexity science to complex thinking: Organisation as simple location. Organization, 5: https://doi.org/10.1177\%2F135050849853003

[27] Tsoukas, H. (1998). Chaos, complexity and organization theory. Organization, 5: 291-313. https://doi.org/10.1177\%2F135050849853001

[28] Gabriel, Y. (1998). The hubris of management. Administrative Theory and Praxis, 20: 257-273.

[29] Anderson, P. (1999). Complexity theory and organizational science. Organization Science, 10(3): 216-232. https://www.jstor.org/stable/i345334

[30] Boisot, M., Child, J. (1999). Organisations as adaptive systems in complex environments. Organization Science, 10(3): 237-252. https://doi.org/10.1287/orsc.10.3.237

[31] Frank, K., Fahrbach, K. (1999). Organisational culture as a complex system: Balance and information in models of influence and selection. Organization Science, 10(3): 257-277. https://doi.org/10.1287/orsc.10.3.253

[32] Stacey, R. (1993). Strategy as order emerging from chaos. Long Range Planning, 26(1): 10-17. https://doi.org/10.1016/0024-6301(93)90228-8

[33] Stacey, R. (2002). Strategic Management and Organisational Dynamic: The Challenge of Complexity. FT Prentice Hall, London, UK.

[34] Lissack, M.R. (1997). Of chaos and complexity: Managerial insights from a new science. Management Decision, 35(3): 205-218. https://doi.org/10.1108/00251749710169413

[35] Beeson, I., Davis, C. (2000). Emergence and accomplishment in organisational change. Journal of Organisational Change Management, 13(2): 178-189. https://doi.org/10.1108/09534810010321508

[36] Dhillon, G., Ward, J. (2002). Chaos theory as a framework for studying information systems. Information Resources Management Journal (IRMJ), 15(2): 1-13. https://doi.org/10.4018/irmj.2002040101

[37] Merali, Y. (2006). Complexity and information systems: The Emergent Domain. Journal of Information Technology, 21(4): 216-228. 
https://doi.org/10.1057\%2Fpalgrave.jit.2000081

[38] McBride, N. (2005). Chaos theory as a model for interpreting information systems in organizations. Information Systems Journal, 15(3): 233-254. https://doi.org/10.1111/j.1365-2575.2005.00192.x

[39] Velásquez Ceballos, H., Restrepo Restrepo, J.H. (2012). Análisis del índice general de la bolsa de valores de colombia y sus rendimientos desde la teoría del caos. Semestre Económico, 15(31): 79-98. https://doi.org/10.22395/seec.v15n31a3

[40] Ndofor, H.A., Fabian, F., Michel, J.G. (2018). Chaos in industry environments. IEEE Transactions on Engineering Management, 65(2): 191-203. https://doi.org/10.1109/TEM.2017.2787860

[41] Radzicki, M.J. (1990). Institutional dynamics, deterministic chaos, and self-organizing systems. Journal of Economic Issues, 24(1): 57-102. https://doi.org/10.1080/00213624.1990.11505001

[42] Butler, A. (1990). A methodological approach to chaos: Are economists missing the point? Federal Reserve Bank of St. Louis, 72(13): 36-48.

[43] Thom, R. (1975). Structural Stability and Morphogenesis. Benjamin, London.

[44] Graham, R.J., Seltzer, J. (1979). An application of catastrophe theory to management science process. Omega, 7(1): 61-66. https://doi.org/10.1016/03050483(79)90024-0

[45] Wright, D.J. (1983). Catastrophe theory in management forecasting and decision making. Journal of the Operational Research Society, 34(10): 935-942. https://doi.org/10.1057/jors.1983.206

[46] Hill, T., Westbrook, R. (1997). SWOT analysis: It's time for a product recall. Long Range Planning, 30(1): 46-52. https://doi.org/10.1016/S0024-6301(96)00095-7

[47] Panagiotou, G. (2003). Bringing SWOT into focus. Business Strategy Review, 14(2): 8-10. https://doi.org/10.1111/1467-8616.00253

[48] Rzevski, G. (2017). Harnessing the power of selforganisation. Complex Systems: Theory and Applications. WIT Press, Southampton, 38(4): 1-12.
https://doi.org/10.25300/MISQ/2014/38.4.09

[49] Pérez, R.A., Massoni, S. (2009). Hacia una teoría general de la estrategia. Barcelona: Ariel.

[50] Henderson, A.D., Miller, D., Hambrick, D.C. (2006). How quickly do CEOs become obsolete? Industry dynamism, CEO tenure, and company performance. Strategic Management Journal, 27(5): 447-460. https://doi.org/10.1002/smj.524

[51] Smallman, C. (1996). Risk and organizational behaviour: a research model. Disaster Prevention and Management, $5(2)$ : 12-26. https://doi.org/10.1108/09653569610112880

[52] Meyer, A.D., Brooks, G.R., Goes, J.B. (1990). Environmental jolts and industry revolutions: Organizational responses to discontinuous change. Strategic Management Journal, 11: 93-110.

[53] Prahalad, C.K., Hamel, G. (1994). Strategy as a field of study: Why search for a new paradigm? Strategic Management Journal, 15(S2): 5-16. https://doi.org/10.1002/smj.4250151002

[54] Resnick, Mitchel (2001). Tortugas, Termitas y Atascos de Tráfico. Barcelona, Editorial Gedisa.

[55] MacIntosh, R., MacLean, D. (2001). Conditioned emergence: researching change and changing research. International Journal of Operations \& Production Management, 21(10): 1343-1357. https://doi.org/10.1108/EUM0000000005973

[56] Niell, F.X. (2012). Estructuras disipativas en la organización de los sistemas bentónicos. Oecologia Aquatica, 5(5): 239-245.

[57] Porter, M.E. (1998). Cluster and the new economics of competition. Harv Bus Rev., 76(6): 77-90.

[58] Porter, M.E. (2000). Location, competition, and economic development: Local clusters in a global economy. Economic Development Quarterly, 14(1): 1534. https://doi.org/10.1177\%2F089124240001400105

[59] Lee, H.L., Padmanabhan, V., Whang, S. (1997). The bullwhip effect in supply Chains. Sloan Management Review, 38(3): 93-102. 